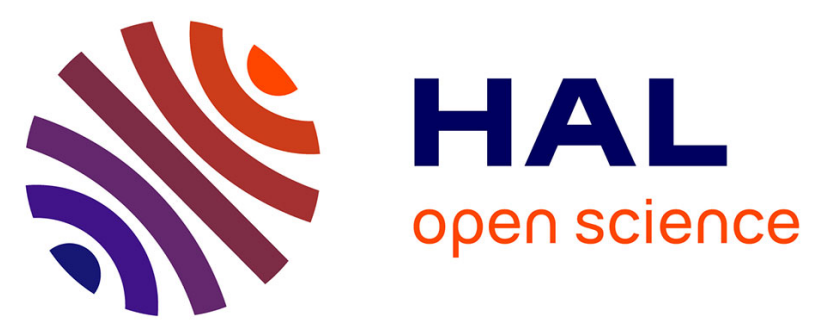

\title{
Structural and magnetic properties of Nd-Fe-Mo-(N) melt-spun ribbons with ThMn12 structure
}

Alex Aubert, Rajasekhar Madugundo, A.M. M Schönhöbel, Daniel Salazar, J.S. S Garitaonandia, J.M. M Barandiaran, G. Hadjipanayis

\section{To cite this version:}

Alex Aubert, Rajasekhar Madugundo, A.M. M Schönhöbel, Daniel Salazar, J.S. S Garitaonandia, et al. Structural and magnetic properties of Nd-Fe-Mo-(N) melt-spun ribbons with ThMn12 structure. Acta Materialia, 2020, 195, pp.519 - 526. 10.1016/j.actamat.2020.05.045 . hal-03049455

\section{HAL Id: hal-03049455 https://hal.science/hal-03049455}

Submitted on 9 Dec 2020

HAL is a multi-disciplinary open access archive for the deposit and dissemination of scientific research documents, whether they are published or not. The documents may come from teaching and research institutions in France or abroad, or from public or private research centers.
L'archive ouverte pluridisciplinaire HAL, est destinée au dépôt et à la diffusion de documents scientifiques de niveau recherche, publiés ou non, émanant des établissements d'enseignement et de recherche français ou étrangers, des laboratoires publics ou privés. 


\title{
Structural and magnetic properties of Nd-Fe-Mo-(N) melt-spun ribbons with $\mathrm{ThMn}_{12}$ structure
}

\author{
A. Aubert ${ }^{\mathrm{a}, *}$, R. Madugundo ${ }^{\mathrm{a}}$, A.M. Schönhöbel ${ }^{\mathrm{a}}$, D. Salazar ${ }^{\mathrm{a}}$, J.S. Garitaonandia ${ }^{\mathrm{b}}$, J.M. \\ Barandiaran $^{\mathrm{a}, \mathrm{b}}$, G. Hadjipanayis ${ }^{\mathrm{c}}$ \\ ${ }^{a}$ Basque Center for Materials, Applications and Nanostructures (BCMaterials), Leioa, Spain \\ ${ }^{b}$ University of the Basque Country (UPV/EHU), Leioa, Spain \\ ${ }^{c}$ University of Delaware, Newark, DE, USA
}

\begin{abstract}
The influence of quenching rate and nitrogenation in melt-spun $\mathrm{Nd}_{1.2} \mathrm{Fe}_{10.6} \mathrm{Mo}_{1.4}$ has been investigated in terms of microstructure, phase formation and magnetic properties. Increasing the quenching rate leads to smaller grain size. However, it also implies a change in the crystallized phase structure. We obtained a pure $\operatorname{ThMn}_{12}(1: 12)$ structure at quenching rates up to $30 \mathrm{~m} / \mathrm{s}$, leading to an average grain size of $220 \mathrm{~nm}$. Magnetic measurements of the as-spun ribbons revealed a reduction of the saturation magnetization for samples quenched above $30 \mathrm{~m} / \mathrm{s}$. This is attributed to the formation of a paramagnetic phase and/or magnetic phase with a Curie temperature $\left(\mathrm{T}_{C}\right)$ close to room temperature which is confirmed by ${ }^{57} \mathrm{Fe}$ Mössbauer spectroscopy. The analysis of the spectra rules out the presence of a ferromagnetic $\mathrm{TbCu}_{7}$ (1:7) phase, which is usually reported in such system. The ribbons were nitrogenated in order to form the harder magnetic phase $\mathrm{Nd}_{1.2} \mathrm{Fe}_{10.6} \mathrm{Mo}_{1.4} \mathrm{~N}_{x}$. The ribbon quenched at $30 \mathrm{~m} / \mathrm{s}$ with the pure $\mathrm{ThMn}_{12}$ nitride structure is the optimum sample for getting hard magnetic properties, with a coercivity of $0.6 \mathrm{~T}$, saturation magnetization of $1.15 \mathrm{~T}$ and Curie temperature of $350{ }^{\circ} \mathrm{C}$. Finally, we show the good stability of the later phase structure at elevated temperatures $\left(\leq \mathrm{T}_{C}\right)$, making this compound a good candidate for permanent magnet applications.
\end{abstract}

Keywords: $\mathrm{ThMn}_{12}$ structure, nitrides, hard magnets, melt spinning, paramagnetism

doi: 10.1016/j.actamat.2020.05.045

\footnotetext{
${ }^{*}$ Corresponding author

Email address: aubert.alex@outlook.fr (A. Aubert)
} 


\section{Introduction}

High-performance permanent magnets are the key components for electrical motors and generators, which are nowadays in increased demand devices for sustainable and greener energy, such as wind turbines, electric vehicles and power electronics. The most commonly used magnets for such purpose are the well-known $\mathrm{Nd}_{2} \mathrm{Fe}_{14}$ B-based ones. Even though this intermetallic compound is the most powerful magnet on the market, the recent 2010/2011 rare-earth crisis has demonstrated the risk of supply and price unpredictability of rareearth elements. Consequently, a renewed interest in rare-earth free and/or lean permanent magnets has come up in the academic and industrial scientific community $[1,2]$.

Although discovered in the late 80 's of the last century $[3,4]$, the tetragonal $\mathrm{R}(\mathrm{Fe}, \mathrm{M})_{12}$ compounds (where R: rare-earth, M:transition metal) having the $\mathrm{ThMn}_{12}$-type structure (1:12) are of increased interest again. Indeed, recently, a wide number of studies report the ability of these compounds to fulfil the criteria to replace the NdFeB-based magnets $[2,5-9]$. The transition metal $\mathrm{M}$ is needed to stabilize the 1:12 structure, but it has an adverse effect in the magnetization and Curie temperature of such compounds, which force its content to be a minimum. On the other hand, for Nd-based 1:12 structures, a spin reorientation around $140 \mathrm{~K}$ was reported in several studies, suggesting an easy magnetization direction (EMD) c-axis at room temperature, but predominantly determined by a Fe-sublattice anisotropy thus leading to a weak net anisotropy $(<1 \mathrm{~T})$ [10-12].

However, in the 90's, studies of nitrogenation of the compounds $\mathrm{Nd}(\mathrm{Fe}, \mathrm{M}){ }_{12} \mathrm{~N}_{x}(\mathrm{M}=\mathrm{Ti}$, Mo, V) with the 1:12 structure reported excellent intrinsic magnetic properties [13, 14]. Due to the inclusion of the interstitial nitrogen, it was observed that the EMD c-axis was changed to a strong uniaxial anisotropy predominantly determined by Nd-sublattice anisotropy [1012]. Hence, the anisotropy is greatly improved at room temperature due to the crystal field created at the $\mathrm{Nd}$ by the pair of $\mathrm{N}$ neighbours along the c-axis. Nitrogenation of 1:12 compounds also results in an increase of both the Curie temperature and magnetization saturation [15].

In the 1:12 nitrides compounds, the selection of the transition element $\mathrm{M}(\mathrm{M}=\mathrm{Ti}, \mathrm{V}$ or Mo) also influences the magnetic properties. For a similar content of transition metal element, previous studies showed that $\mathrm{NdFe}_{11} \mathrm{TiN}_{x}$ and $\mathrm{NdFe}_{11} \mathrm{MoN}_{x}$ have similar magnetization saturation, whereas slightly higher values were reported for $\mathrm{NdFe}_{10} \mathrm{~V}_{2} \mathrm{~N}_{x}$ compared to $\mathrm{NdFe}_{10} \mathrm{Mo}_{2} \mathrm{~N}_{x}[13,16]$. Moreover, in the 1:12 nitrides, the anisotropy field is correlated with the ability of the system to absorb nitrogen (i.e. the expansion rate $\delta V / V$ ) which also shows dependence to the transition metal M. Based on previous reports, the highest anisotropy field is reported for Mo as transition element in comparison with $\mathrm{Ti}$ and $\mathrm{V}$ [13, 16]. Furthermore, the use of Mo allows a better stability of the 1:12 phase than the $\mathrm{Ti}$ [17-19] and a larger coercivity than the $\mathrm{V}$ or $\mathrm{Ti}[16]$. Thus, among these compounds, the best candidate to show hard magnetic properties seems to be the $\mathrm{Nd}(\mathrm{Fe}, \mathrm{Mo}){ }_{12} \mathrm{~N}_{x}$.

However, most of the investigations reporting hard magnetic properties of the NdFeMobased alloys were done for the $\mathrm{NdFe}_{10} \mathrm{Mo}_{2} \mathrm{~N}_{x}$. Thus, the saturation magnetization and the Curie temperature are not optimized from a chemical composition point of view, as the Fe content is reduced to 10 atom/f.u. and can be increased to 10.5 atom/f.u. [20-23], 
still keeping a stable 1:12 phase. In this study, we decided to increase the Fe content to 10.6 atom/f.u.. Above this amount, it is difficult to stabilize the 1:12 phase and a lower coercivity is expected [16]. Moreover, the coercive field is known to mostly depend on the microstructure (i.e. grain size) and the nitrogen content (magnetocrystalline anisotropy), thus making the sample preparation process important in these alloys [20]. Melt-spinning is the most promising technique to control the microstructure as it allows to directly control the grain size by changing the quenching rate (i.e. wheel speed) during the process. Hence, the few studies reporting high coercivity (approx. $1 \mathrm{~T}$ ) for $\mathrm{NdFe}_{10.5} \mathrm{Mo}_{1.5} \mathrm{~N}_{x}$ are obtained at high quenching rates $(\geq 45 \mathrm{~m} / \mathrm{s})$ to achieve very fine microstructure. However, such high rates

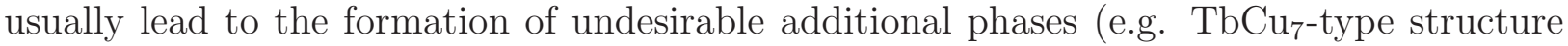
(1:7), amorphous phase, etc.) besides the wanted 1:12 structure [20, 21, 24]. Hence, prior to nitrogenation, samples must be annealed for a short time under vacuum in order to recover a quasi pure 1:12 system without inducing grain growth [20, 21, 25]. Nonetheless, during the annealing process, other structures than the $\mathrm{ThMn}_{12}$ can easily be formed (e.g. $\mathrm{CaCu}_{5}$, $\mathrm{TbCu}_{7}, \mathrm{Th}_{2} \mathrm{Zn}_{17}$, or $\mathrm{Y}_{3} \mathrm{Fe}_{29}$ ) due to the complex phase diagram for such system. As these phases exhibit very close x-ray diffraction patterns, it is difficult to distinguish the existing phases and their respective amounts can be misleading [19].

In this study, we first focus on obtaining pure $\mathrm{ThMn}_{12}$ melt-spun ribbons with submicron grain size by varying the quenching rate. Then, we investigate the structural, magnetic properties and hyperfine interactions of these ribbons to better understand the precursors characteristics prior to nitrogenation. Here, we did not perform any annealing process in order to compare their properties as a function of the wheel speed and avoid the formation of additional structures in the precursors. Then, we compare the structural, magnetic properties and hyperfine interactions of the nitrides with the as-spun samples. It is shown that hard magnetic properties strongly depend on the microstructure of the precursors as well as their purity. The stability of the structure as function of temperature is also examined for our pure $\mathrm{ThMn}_{12}$ nitride sample with the most promising hard properties.

\section{Experimental Details}

Ingots with a nominal composition $\mathrm{Nd}_{1.2} \mathrm{Fe}_{10.6} \mathrm{Mo}_{1.4}$ were prepared by arc-melting using 99.9\% pure metals. A Nd excess of $20 \%$ was added as Pinkerton et al. reported the best magnetic properties for such composition [24]. Another study suggests that this excess promotes the precipitation of Nd-rich intergranular phase, which could play a key role in hard magnetic properties for this compound [26]. The obtained alloys were then melt-spun by ejecting the molten alloy through an orifice $(0.8 \mathrm{~mm})$ from the bottom of a quartz tube onto a copper wheel in an argon atmosphere. The quench rate was varied by changing the linear wheel velocity $(\nu)$, using the values of $10,30,35$ and $44 \mathrm{~m} / \mathrm{s}$. The ribbons were then crushed into particles with sizes below $38 \mu \mathrm{m}$. The powder was sealed in a quartz tube in an atmosphere of approx. 0.9 bar $\mathrm{N}_{2}$ gas and the nitrogenaiton process was optimized in temperature and time using the $30 \mathrm{~m} / \mathrm{s}$ as-spun ribbons. The best magnetic properties were obtained by heating at $600{ }^{\circ} \mathrm{C}$ for 3 hours followed by a quench in water. 


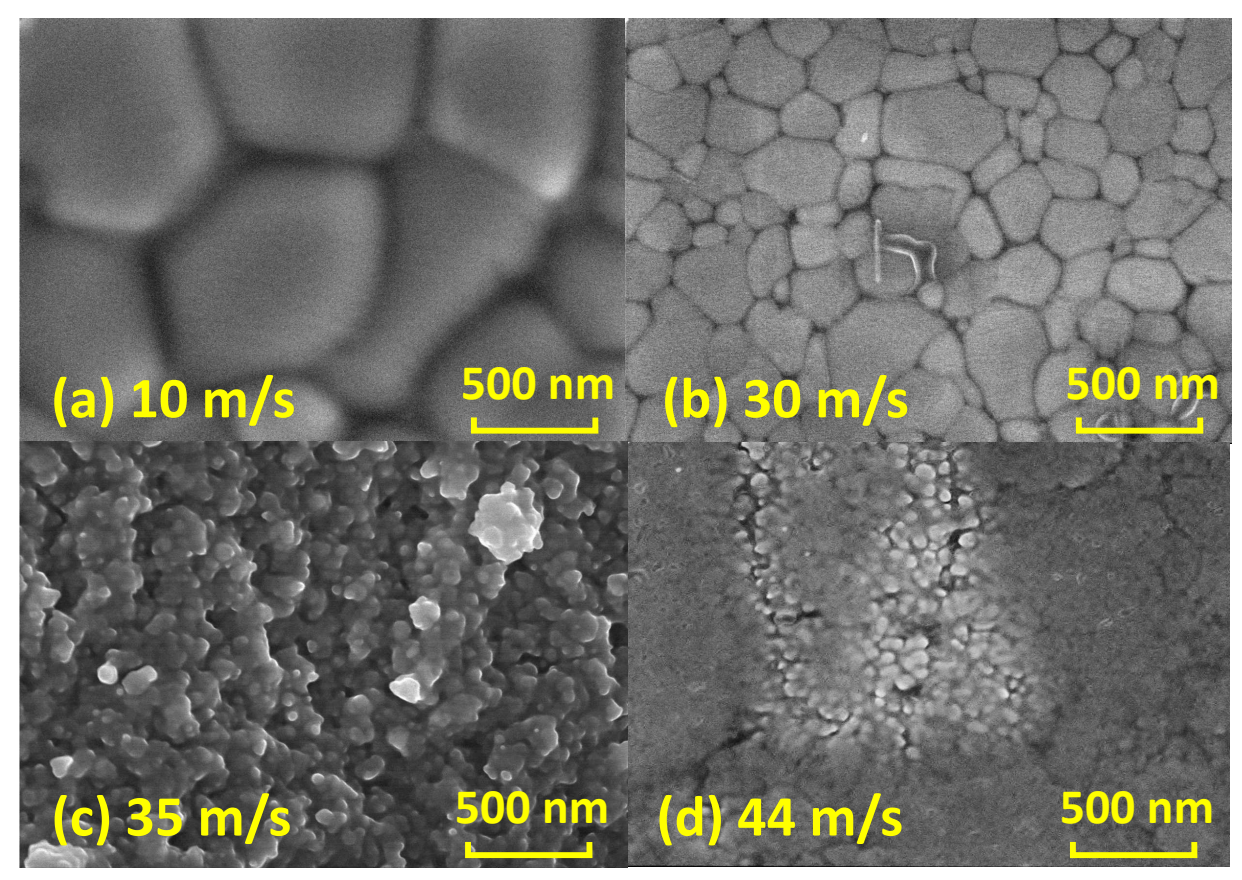

Figure 1: FEG-SEM images of the ribbons melt-spun at (a) $10 \mathrm{~m} / \mathrm{s}$, (b) $30 \mathrm{~m} / \mathrm{s}$, (c) $35 \mathrm{~m} / \mathrm{s}$ and (d) $44 \mathrm{~m} / \mathrm{s}$.

The morphologies of the ribbons were studied using a Hitachi S-4800 field-emission scanning electron microscope (FE-SEM) at an acceleration voltage of $10 \mathrm{kV}$. The structure of the non-nitrided and nitrided powder was determined by X-ray diffraction (XRD) using $\mathrm{CuK} \alpha$ radiations. ${ }^{57} \mathrm{Fe}$ Mössbauer spetra were collected at room temperature in a constant acceleration spectrometer with transmission geometry, using a $\mathrm{Co}(\mathrm{Rh})$ source calibrated with an iron foil. Magnetic measurements were performed using $2 \mathrm{~T}$ (Microsense) and 14 T (Quantum Design) vibrating sample magnetometers (VSM). The thermogravimetry analysis was done using a TGA/SDTA 851e Mettler Toledo under air. The X-ray diffraction pattern as function of temperature was performed in Bruker D8 Advance Vantec under air using a platinum foil heater.

\section{Results and discussion}

\subsection{As-spun $\mathrm{Nd}-\mathrm{Fe}-\mathrm{Mo}$}

\subsubsection{Microstructure}

The morphology and microstructure of the ribbons quenched at various cooling rates are shown in Figure 1. As expected, we observe a decrease of the grain size by increasing the quenching rate. Grains can perfectly be distinguished in the 10 and $30 \mathrm{~m} / \mathrm{s}$ quenched samples whereas grain boundaries become less evident when increasing the wheel speed above $30 \mathrm{~m} / \mathrm{s}$. Hence, it was difficult to determine a precise grain size for the 35 and $44 \mathrm{~m} / \mathrm{s}$. Nevertheless, based on the SEM pictures, the average grain size is estimated to be 650,220 , 100 and $50 \mathrm{~nm}$ for the $10,30,35$ and $44 \mathrm{~m} / \mathrm{s}$ ribbons, respectively. If we compare to the results reported by Lin et al., the grain size obtained at a given wheel speed is larger in our 


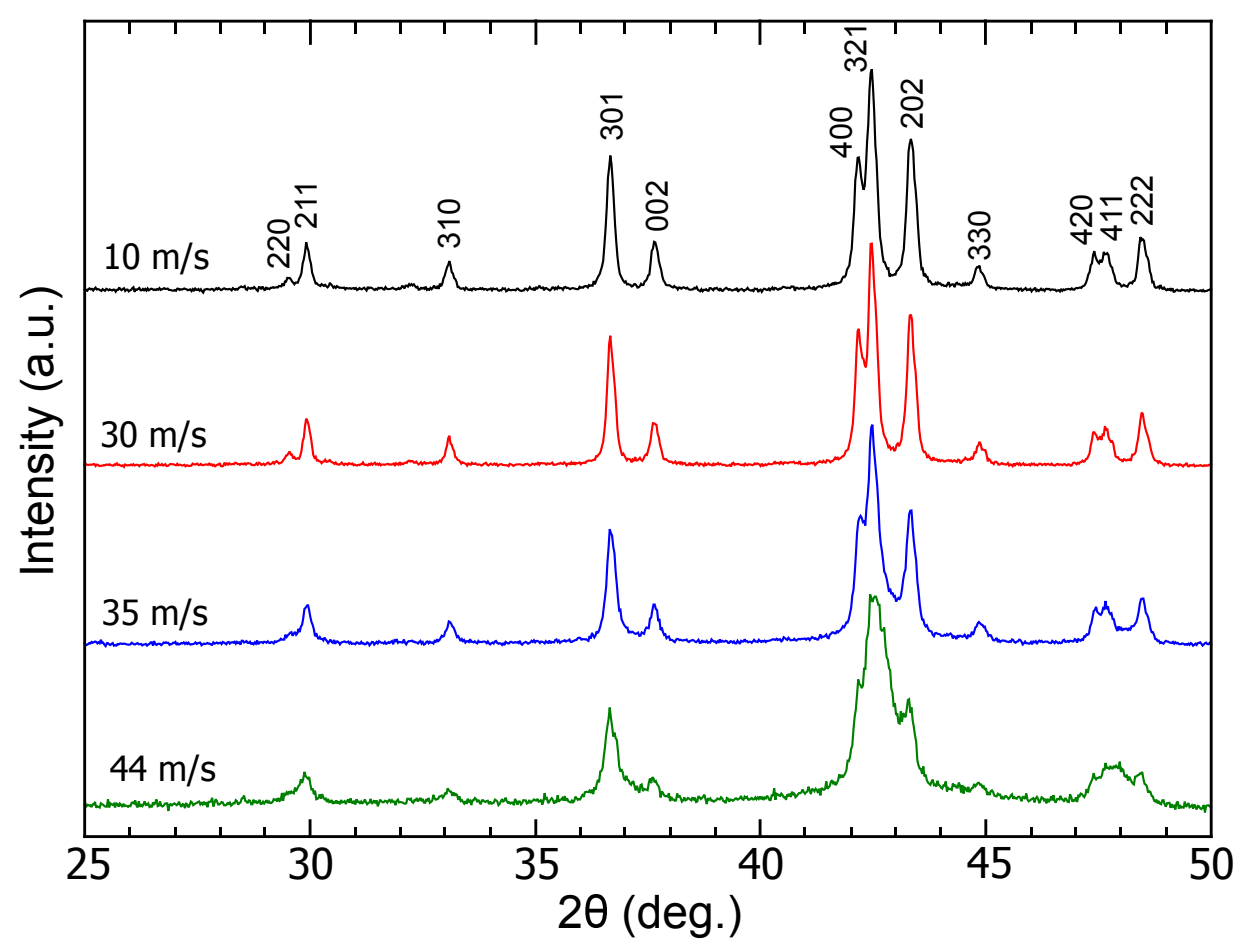

Figure 2: X-ray diffraction patterns of $\mathrm{Nd}_{1.2} \mathrm{Fe}_{10.6} \mathrm{Mo}_{1.4}$ ribbons melt-spun at various wheel speed.

case [21]. This can be due to the melt spinner's parameters, like the ejection pressure, the nozzle orifice or the wheel gap, which influence the quenching rate during the process [27]. It can also be a consequence of the lower amount of Mo in the composition [21].

Additionally, the limitation of our microscope didn't allow us to investigate further the interganular phase. However, for such system, it is expected to form 1:12 grains surrounded by a Nd-rich phase grain boundaries, which is due to the excess $\mathrm{Nd}$ added in the composition. This feature was observed in our arc melted ingots and were also reported in previous 1:12 compounds $[19,26]$.

XRD patterns of the ribbons quenched at different wheel speeds are shown in Figure 2. For quenching rates below or equal to $30 \mathrm{~m} / \mathrm{s}$, we observe a single phase with the $\mathrm{ThMn}_{12^{-}}$ type structure. On the other hand, at high quenching rate, we observe a large broadening of the peaks. This should mostly be due to the finer grain size [25]. It was also reported that it could be the consequence of phase transition, most possibly from the $\mathrm{ThMn}_{12}$ structure to the disordered $\mathrm{TbCu}_{7}(1: 7)$ structure as well as amorphisation of the crystalline phase [20, 21, 24]. However, we will show in the section 3.1.3 that the presence of a ferromagnetic $\mathrm{TbCu}_{7}$ phase in this compound is very unlikely while amorphisation seems consistent.

\subsubsection{Magnetic properties}

Thermo-magnetic measurements $\mathrm{M}(\mathrm{T})$ were performed in all the as-spun ribbons and the results are presented in Figure 3. For quenching rates below or equal to $30 \mathrm{~m} / \mathrm{s}$, we observe a single phase thermomagnetic curve, with a $T_{C}$ of approximately $160{ }^{\circ} \mathrm{C}$, which is in good agreement with previous values reported for Nd-Fe-Mo [16]. For higher quenching rates, 


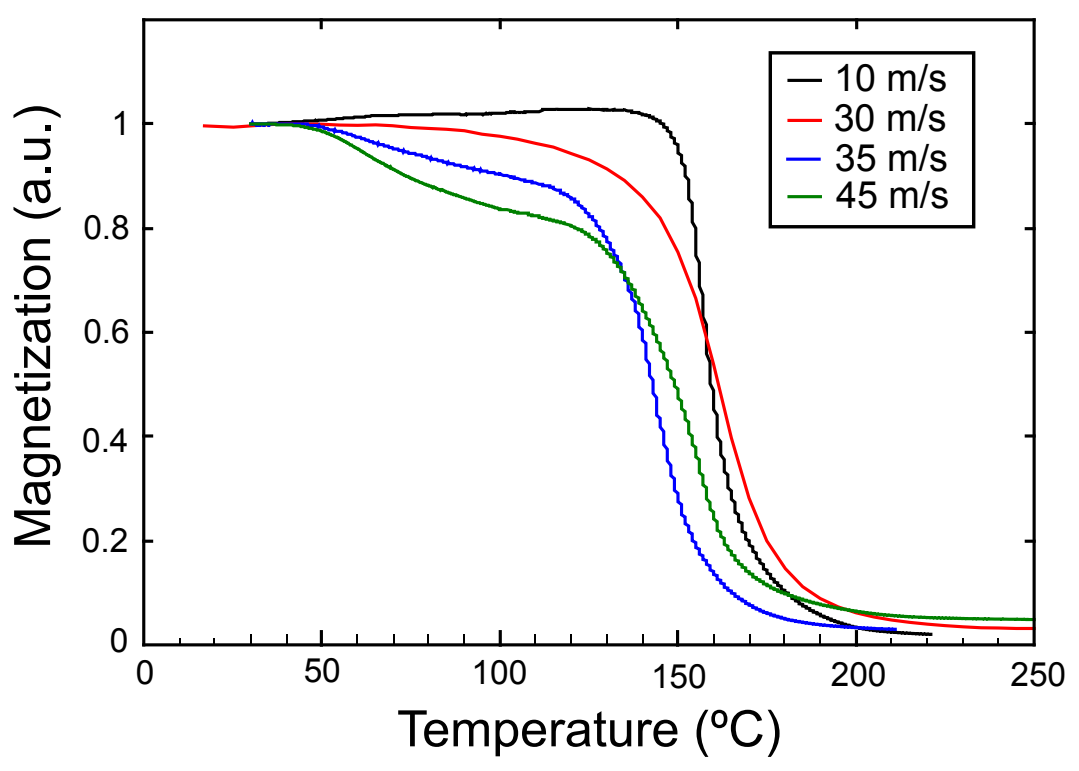

Figure 3: $\mathrm{M}(\mathrm{T})$ measurements of as-spun ribbons for $\mu_{0} H_{a}=10 \mathrm{mT}$.

we observe two magnetic ordering transitions, the first one around $60{ }^{\circ} \mathrm{C}$ and the second one - related with the $1: 12$ phase - at $150{ }^{\circ} \mathrm{C}$. Regarding the first transition temperature, it could be attributed to an amorphous phase as reported in Nd-Fe-B system [28]. The pure $\mathrm{NdFe}_{7}\left(\mathrm{TbCu}_{7}\right)$ is expected to have a transition at $103{ }^{\circ} \mathrm{C}$ [29], which can hardly be assessed here. Nevertheless, thermo-magnetic measurements confirm that we obtain nonpure $\mathrm{ThMn}_{12}$ ribbons when they are melt-spun at a wheel speed above $30 \mathrm{~m} / \mathrm{s}$.

To further characterize the samples, magnetic hysteresis loops were recorded on the as-spun ribbons. Based on these measurements, we report in Figure 4 the saturation magnetization $\left(M_{S}\right)$ and coercive field $\left(H_{C}\right)$ for the different samples. With increasing the wheel
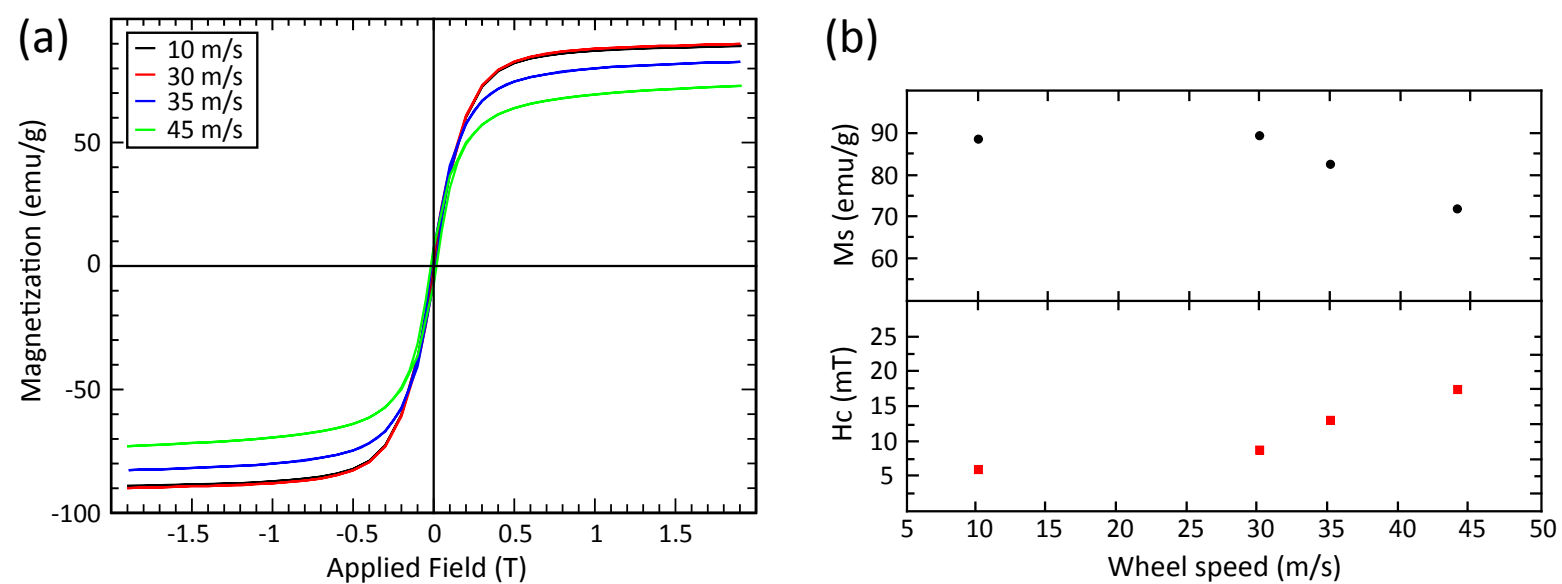

Figure 4: (a) M-H loop of the as spun $\mathrm{Nd}_{1.2} \mathrm{Fe}_{10.55} \mathrm{Mo}_{1.45}$ ribbons and their (b) saturation magnetization $(\mathrm{Ms})$ and coercive field $(\mathrm{Hc})$ as a function of the quenching rate. 
speed, we observe a decrease of the saturation magnetization from $89 \mathrm{emu} / \mathrm{g}$ - for samples obtained at $\nu \leq 30 \mathrm{~m} / \mathrm{s}$ - to $72 \mathrm{emu} / \mathrm{g}$ at $44 \mathrm{~m} / \mathrm{s}$. This corresponds to a decrease of $20 \%$ in the saturation magnetization, which could be explained by the presence of the above mentioned amorphous (or disorder) phase with a $\mathrm{T}_{C}$ close to room temperature in these samples. The increase in wheel speed also implies a slight raise of the coercive field from 6 (@ $10 \mathrm{~m} / \mathrm{s}$ ) to $17.5 \mathrm{mT}$ (@ $44 \mathrm{~m} / \mathrm{s}$ ) due to the decrease of the grains size.

\subsubsection{Hyperfine interactions}

The hyperfine interactions in our samples were also investigated by Mössbauer spectroscopy. Figure 5 (a) shows the spectrum at room temperature of the sample melt-spun at $30 \mathrm{~m} / \mathrm{s}$ with their fitting components. This sample was chosen because it presents a pure $\mathrm{ThMn}_{12}$ structure. In Nd-Fe-Mo alloys, the Mo atoms substitutes Fe atoms exclusively in the 8i position. Consequently, the Fe atoms of the $8 \mathrm{i}, 8 \mathrm{j}$ and $8 \mathrm{f}$ crystallographic sites in the $\mathrm{ThMn}_{12}$ type alloys are subjected to different atomic environments and the spectra from the three Fe crystallographic sites are split. The relative intensity of the different subspectra can be calculated by a binomial distribution. Thus, each $8 \mathrm{i}$ sites splits into 6 subspectra and the $8 \mathrm{f}$ and $8 \mathrm{j}$ ones into 5. Only subspectra having 0 Mo, 1 Mo, 2 Mo or 3 Mo atoms in the neighbourhood of the corresponding Fe atom present relative intensities higher than $2 \%$. Hence, the spectrum has been fitted with 12 discrete components by taking 4 possible neighbourhoods for each Fe crystallographic position (8i, 8j, 8f) [10, 30, 31]. In order to minimize the number of fitting parameters, hyperfine field and isomer shift of each Fe crystallographic site have been assumed to vary linearly with the number of Mo atoms in their neighbourhood. The quadrupolar shifts also vary consistently with the number of Mo atoms in the neighbourhood of each Fe crystallographic position. The hyperfine fields for the Fe sites decrease in the order $B_{h f}(8 \mathrm{i})>B_{h f}(8 \mathrm{j})>B_{h f}(8 \mathrm{f})$, consistently to the decreasing obtained for the isomer shift. The obtained average values of the hyperfine parameters of this sample are reported in Table 1.

Mössbauer spectroscopy at room temperature was also performed on the non-pure $\mathrm{ThMn}_{12}$

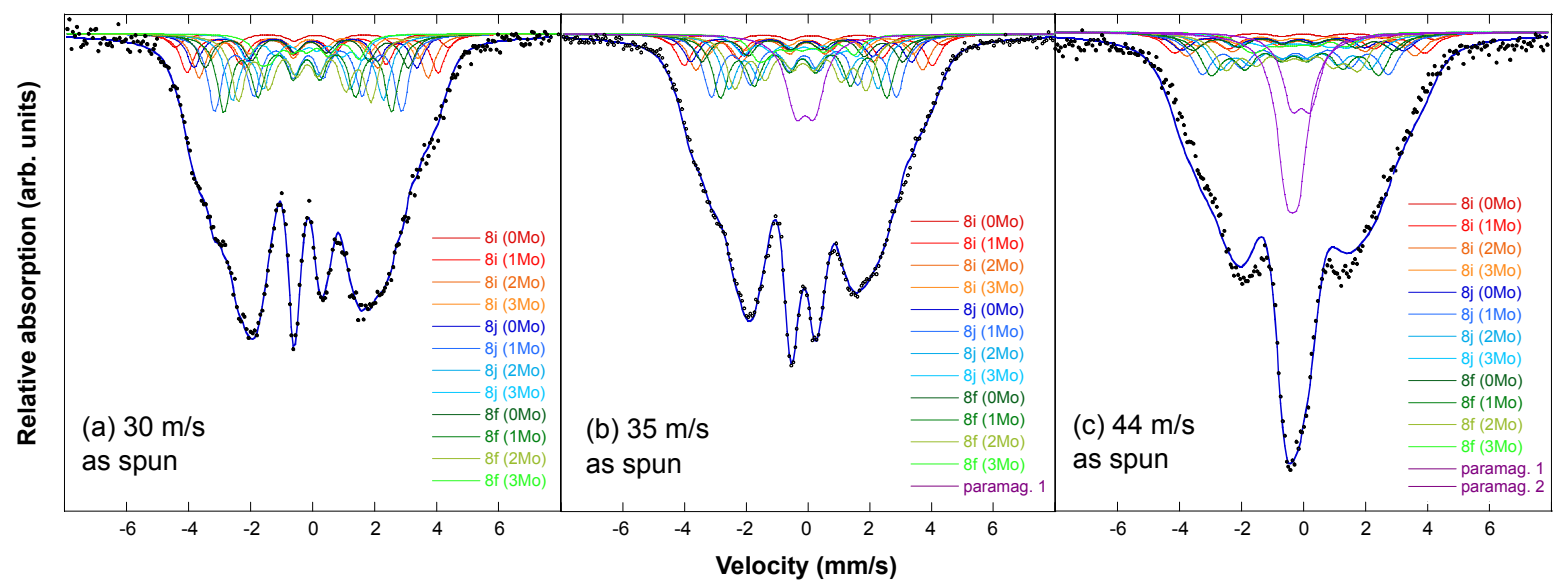

Figure 5: Room temperature Mössbauer spectrum of ribbons melt-spun at (a) $30 \mathrm{~m} / \mathrm{s}$, (b) $35 \mathrm{~m} / \mathrm{s}$ and (c) $44 \mathrm{~m} / \mathrm{s}$. 
Table 1: Mössbauer parameters of $\mathrm{Nd}_{1.2} \mathrm{Fe}_{10.6} \mathrm{Mo}_{1.4}$ melt-spun at $30 \mathrm{~m} / \mathrm{s}$ before and after nitrogenation.

\begin{tabular}{cccccccc}
\hline Fe position & \multicolumn{3}{c}{ Before nitrogenation } & & \multicolumn{3}{c}{ After nitrogenation } \\
\cline { 2 - 4 } \cline { 6 - 8 } & $\mathrm{I}_{\mathrm{S}}(\mathrm{mm} / \mathrm{s})$ & $\mathrm{Q}_{\mathrm{S}}(\mathrm{mm})$ & $\mathrm{B}_{\mathrm{HF}}(\mathrm{T})$ & & $\mathrm{I}_{\mathrm{S}}(\mathrm{mm} / \mathrm{s})$ & $\mathrm{Q}_{\mathrm{S}}(\mathrm{mm})$ & $\mathrm{B}_{\mathrm{HF}}(\mathrm{T})$ \\
\hline $8 \mathrm{i}$ & 0.01 & 0.04 & 23.7 & & 0.07 & 0.17 & 28.5 \\
$8 \mathrm{j}$ & -0.15 & 0.02 & 17.3 & & -0.07 & 0.08 & 22.6 \\
$8 \mathrm{f}$ & -0.19 & -0.01 & 15.4 & & -0.10 & 0.06 & 19.8 \\
\hline
\end{tabular}

as-spun samples (35 and $44 \mathrm{~m} / \mathrm{s}$ ) in order to better understand the magnetic interactions in such system. The spectra are represented in Figure 5 (b) and (c). Here, the fittings were done by replicating and re-scaling the fitting spectrum obtained from the pure 1:12 sample $(30 \mathrm{~m} / \mathrm{s})$ and adding paramagnetic contributions for both 35 and $44 \mathrm{~m} / \mathrm{s}$. As it can be observed in Figure 5 (b) and (c), both experimental spectra are reliably modelled. Taking into account that the profile of the Mössbauer spectrum of $\mathrm{ThMn}_{12}$ compounds highly depends on the $\mathrm{M}$ exact stoichiometry, the observed consistence among the fitting and the experimental spectra of the 35 and $44 \mathrm{~m} / \mathrm{s}$ samples would reflect that the composition of the 1:12 phase in these last samples is also close to $\mathrm{Nd}_{1.2} \mathrm{Fe}_{10.6} \mathrm{Mo}_{1.4}$. Based on these results, approximately 8 at.\% and 21 at.\% of Fe is expected to be in the paramagnetic state for 35 and $44 \mathrm{~m} / \mathrm{s}$, respectively. This amount is coherent with the reduction of saturation magnetization observed in the $\mathrm{M}(\mathrm{H})$ loop in Figure 4.

Hence, samples quenched at a wheel speed above $30 \mathrm{~m} / \mathrm{s}$ contain one crystalline ferromagnetic phase (the 1:12) and one (or several) paramagnetic phase including the observed contribution with a $\mathrm{T}_{C}$ close to room temperature, which has been modelled in the fittings as a wide doublet. In the literature, at such high wheel speed, it is usually reported a phase transition from the 1:12 to the disordered 1:7 phase. However, the $\mathrm{NdFe}_{7}$ is ferromagnetic at room temperature with a 13 T hyperfine field [29, 32]. An attempt on adding the 1:7 component in the Mössbauer fitting was done but the results were not consistent. Hence, it is very unlikely that samples quenched above $30 \mathrm{~m} / \mathrm{s}$ contain such phase, at least in a ferromagnetic state.

Regarding the origin of the paramagnetic phase, we can only speculate at this stage. The most probable hypothesis being that the compound contains some binary Fe-Mo amorphous alloy, which was reported to be paramagnetic at room temperature for alloys with more than 28 at\% of Mo [33]. It could also be due to a Nd-rich amorphous or 1:7 disordered phase.

\subsection{Nitrogenated $\mathrm{Nd}-\mathrm{Fe}-\mathrm{Mo}$}

\subsubsection{Microstructure}

Static pressure nitrogenation was performed for all the ribbons at $600{ }^{\circ} \mathrm{C}$ during 3 hours, by sealing the powder in a quartz tube which ensures to have no leaks during the process. It also allows us to achieve a pressure close to 3 bar at $600{ }^{\circ} \mathrm{C}$ if we consider the nitrogen as a perfect gas. The XRD patterns of the nitrides are shown in Figure 6 . We can see that there is a shift to lower scattering angles for every sample. This behavior is attributed to the inclusion of nitrogen into the lattice structure, particularly in the $2 \mathrm{~b}$ sites, leading 


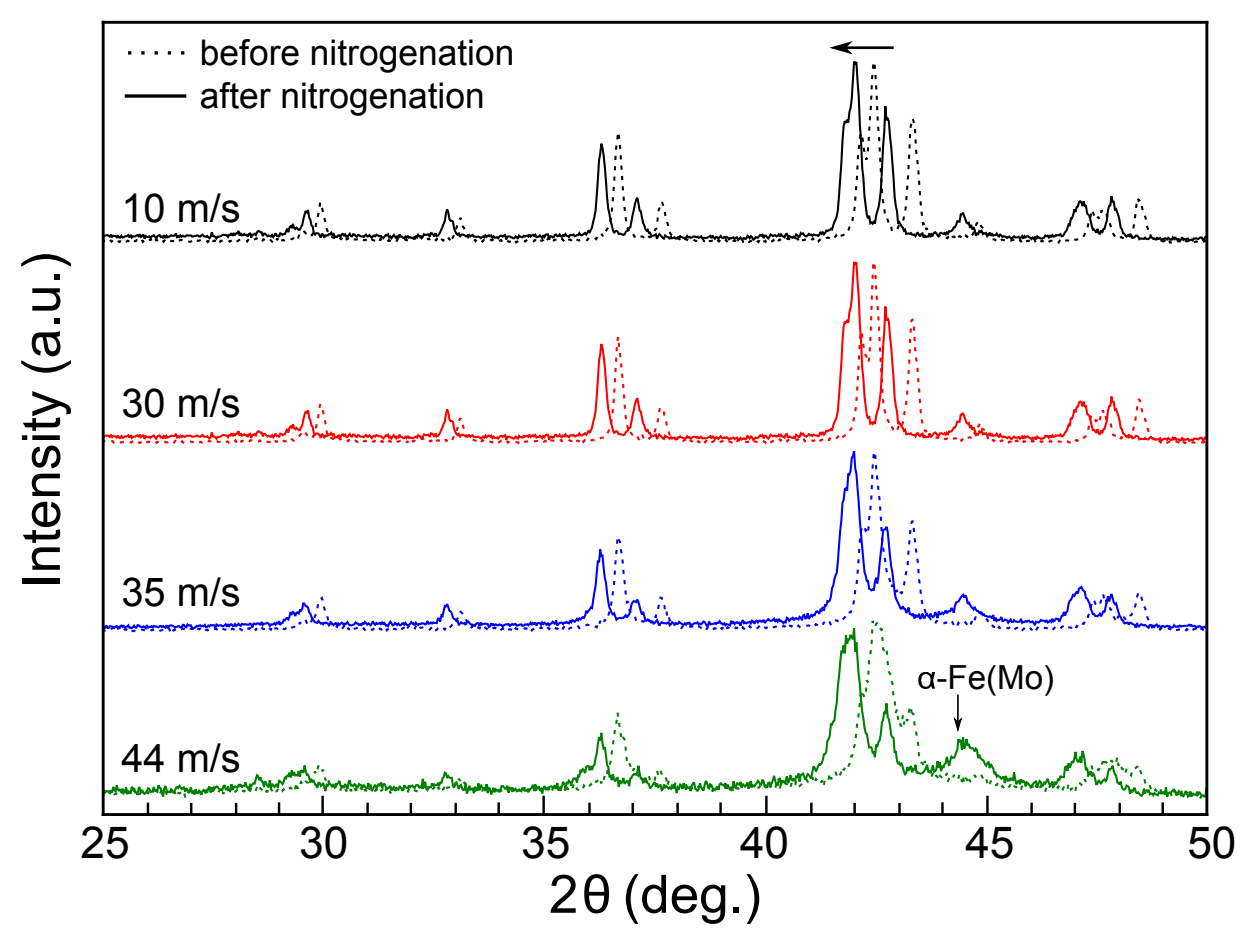

Figure 6: X-ray diffraction patterns of ribbons quenched at different wheel speed, before and after nitrogenation.

to a volume expansion. Le Bail fitting was performed on the as-spun and nitrided sample quenched at $30 \mathrm{~m} / \mathrm{s}$ using the MAUD software. This sample was chosen because it exhibits pure $\mathrm{ThMn}_{12}$ structure. Based on the lattice parameters obtained, the volume expansion was estimated to be $3.4 \%$. This value is close to previous studies, giving a content of one nitrogen atom/f.u. [24, 25]. From the XRD fittings, the crystallites size was also calculated for the as-spun and nitrided sample and their values are reported in Table 2. Almost no increase of the size is observed, meaning that our nitrogenation process does not significantly induce grain growth.

One can note that after nitrogenation, the (330) diffraction peak of the 1:12 structure and the $\alpha$ - $\mathrm{Fe}(\mathrm{Mo})$ peak are almost superimposed (around $44.5^{\circ}$ ), which makes difficult to give an accurate content of $\alpha-\mathrm{Fe}(\mathrm{Mo})$ formed during the nitrogenation process. However, no increase in the intensity at this scattering angle is observed except for the $44 \mathrm{~m} / \mathrm{s}$ sample, which shows a broader and higher intensity peak. Therefore, these results confirm that our nitrogenation process is well performed and that nitrogen gets in the structure even for a non-pure $\mathrm{ThMn}_{12}$ phase system.

\subsubsection{Magnetic properties}

The magnetic hysteresis loops of the nitrided ribbons have been recorded for an applied field of $12 \mathrm{~T}$, and the saturation magnetization and coercive field are plotted as a function of the quenching rate in Figure 7. We observe an improvement of both $\mathrm{Ms}$ and $\mathrm{Hc}$ of the nitrides compared to the parent compounds. The increase of Ms is due to the higher 


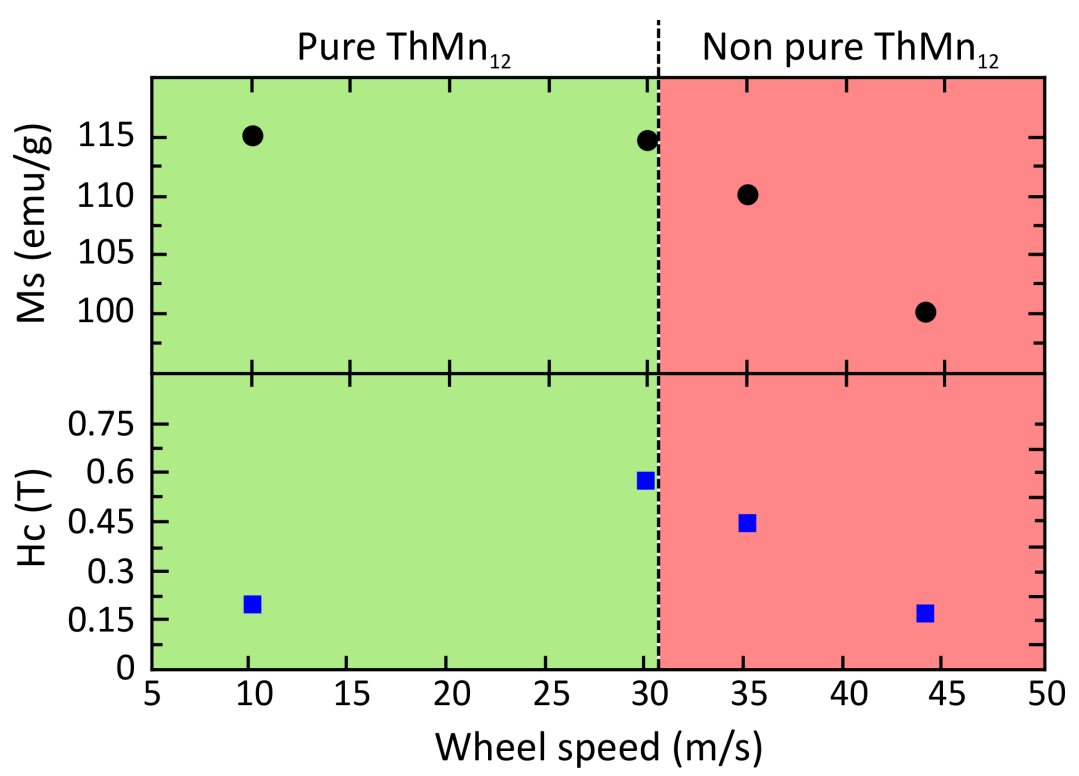

Figure 7: Saturation magnetization and coercive field of $\mathrm{Nd}_{1.2} \mathrm{Fe}_{10.55} \mathrm{Mo}_{1.45} \mathrm{~N}_{x}$ samples as a function of the quenching rate.

magnetic moment of the Fe atom [34], whereas the increase in Hc is the consequence of the strong uniaxial anisotropy induced by the Nd-sublattice anisotropy [12]. Both improvements are consequences of the inclusion of the interstitial $\mathrm{N}$ atom at the $2 \mathrm{~b}$ sites in the $\mathrm{ThMn}_{12}$ structure. Regarding the saturation magnetization, the pure 1:12 nitrided samples exhibit a magnetization of $115 \mathrm{emu} / \mathrm{g}$ which decreases to 110 and $100 \mathrm{emu} / \mathrm{g}$ for the non-pure 35 and $44 \mathrm{~m} / \mathrm{s}$, respectively. This is the consequence of the paramagnetic phase revealed for as-spun ribbons which seems to be still present after nitrogenation. For pure 1:12 samples, the increase in the wheel speed (i.e. lowering of the grain size) allows an enhancement of the coercivity. At $30 \mathrm{~m} / \mathrm{s}$, a coercive field of $0.6 \mathrm{~T}$ is obtained, which is 3 times the coercivity of the $10 \mathrm{~m} / \mathrm{s}$ sample. On the other hand, once a system with paramagnetic contribution is obtained, the increase in quenching rate results in a reduction of the coercivity $(0.16 \mathrm{~T}$ @ $44 \mathrm{~m} / \mathrm{s}$ ). Hence, as reported in a previous study [24], the coercivity in such systems is limited by the grain size and the purity of the phase.

A deeper study of our best nitrided sample (melt-spun at $30 \mathrm{~m} / \mathrm{s}$ ) has been performed by measuring the hysteresis loops with a maximum applied field of $12 \mathrm{~T}$ at room temperature and at $5 \mathrm{~K}$. These loops are plotted and compared with the ones obtained for the as-spun sample in Figure 8. The saturation magnetization $\left(\mathrm{M}_{S}\right)$ and coercive field $\left(\mathrm{H}_{C}\right)$ obtained for the two samples at 5 and $300 \mathrm{~K}$ are reported in Table 2. Both for the as-spun ribbons, we observe an increase of the saturation magnetization and coercive field at low temperature due to the reduction of thermal fluctuation.

The coercive field of the nitrides reaches $2.9 \mathrm{~T}$ at $5 \mathrm{~K}$. However, the magnetization saturation is higher at room temperature than at $5 \mathrm{~K}$. This can be explained by the fact that the nitride at $5 \mathrm{~K}$ is not yet saturated for an applied magnetic field of $12 \mathrm{~T}$. These plots also show that after nitrogenation, the saturation magnetization at room temperature 


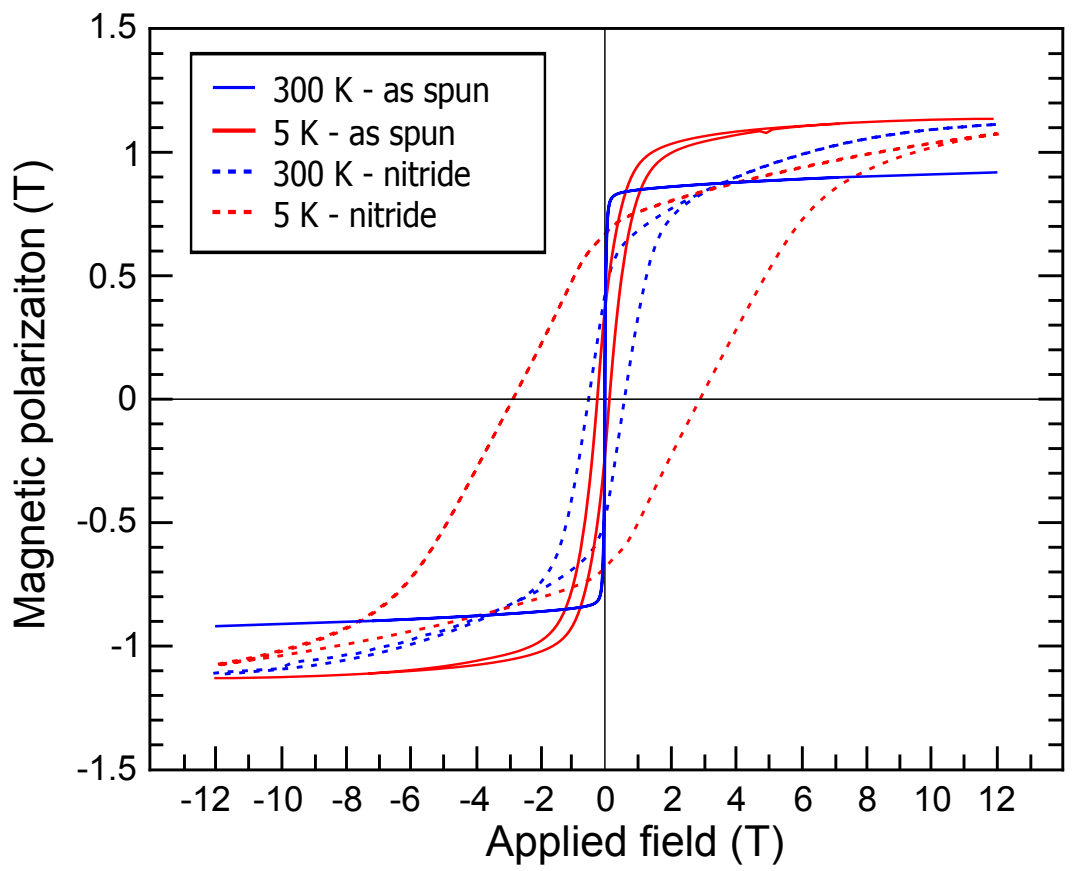

Figure 8: Magnetic hysteresis loops at $300 \mathrm{~K}$ and $5 \mathrm{~K}$ of the as-spun and nitride $\mathrm{Nd}_{1.2} \mathrm{Fe}_{10.55} \mathrm{Mo}_{1.45}$ quenched at $30 \mathrm{~m} / \mathrm{s}$.

Table 2: Properties of $\mathrm{Nd}_{1.2} \mathrm{Fe}_{10.6} \mathrm{Mo}_{1.4}\left(\mathrm{~N}_{x}\right)$ melt-spun at $30 \mathrm{~m} / \mathrm{s}$.

\begin{tabular}{|c|c|c|c|c|c|c|c|}
\hline & \multirow{2}{*}{$\begin{array}{l}\text { Grain size } \\
(\mathrm{nm})\end{array}$} & \multirow{2}{*}{$\begin{array}{c}\text { Cryst. size } \\
\text { (nm) }\end{array}$} & \multicolumn{2}{|c|}{$\mathrm{M}_{S}(@ 12 \mathrm{~T})(\mathrm{T})$} & \multicolumn{2}{|c|}{$\mathrm{H}_{C}(\mathrm{~T})$} & \multirow{2}{*}{$\begin{array}{c}\mathrm{T}_{C} \\
\left({ }^{\circ} \mathrm{C}\right)\end{array}$} \\
\hline & & & (a) $5 \mathrm{~K}$ & @ $300 \mathrm{~K}$ & (a) $5 \mathrm{~K}$ & (a) $300 \mathrm{~K}$ & \\
\hline & 220 & 113 & 1.3 & 0.91 & 0.18 & 0.009 & 160 \\
\hline nitride & $\mathrm{n} / \mathrm{a}$ & 118 & $\mathrm{n} / \mathrm{a}$ & 1.15 & 2.9 & 0.6 & 350 \\
\hline
\end{tabular}

is increased by $25 \%$. As expected, reducing the Mo content to 1.4 allows a higher saturation magnetization than for samples with Mo content above 1.5 [16, 24, 25].

Thermomagnetic measurements were also conducted on the $30 \mathrm{~m} / \mathrm{s}$ nitrogenated sample and the Curie temperature $\left(\mathrm{T}_{C}\right)$ is reported in Table 2. After nitrogenation, $\mathrm{T}_{C}$ is increased to $350{ }^{\circ} \mathrm{C}$, which is $190{ }^{\circ} \mathrm{C}$ higher than the value obtained for the as-spun ribbons, due to the increase in the Fe-Fe interaction. The low Mo content also favours a higher Curie temperature than in other Nd-Fe-Mo-N systems [16, 24].

\subsubsection{Hyperfine interactions}

The Mössbauer spectra at room temperature for both 30 and $44 \mathrm{~m} / \mathrm{s}$ nitrogenated samples are shown in Figure 9. The spectrum of the $30 \mathrm{~m} / \mathrm{s}$ nitride was fitted following the same procedure than for the non-nitrogenated sample already described in section 3.1.3. This hints for a pure 1:12 structure after nitrogenation. The results of the fittings are summarized in Table 1. An increase of the isomer shift after nitrogenation is observed in all the positions, which is due to the volume expansion of approximately $3.4 \%$ based on XRD 


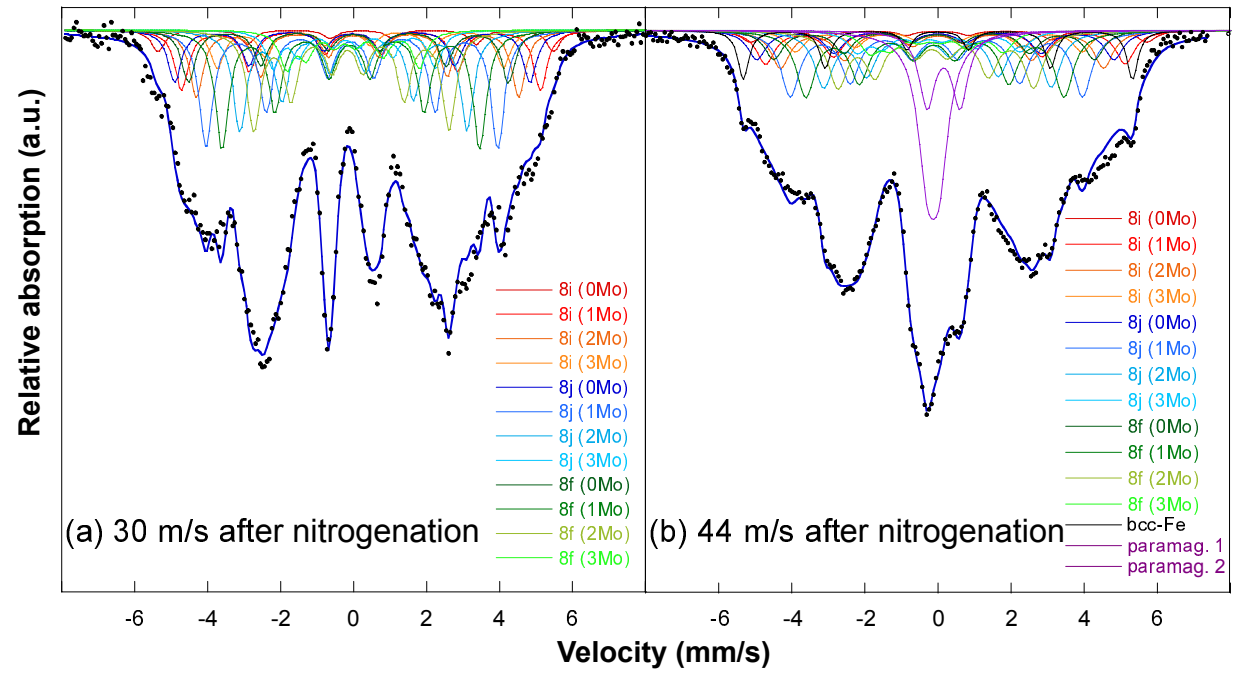

Figure 9: Room temperature Mössbauer spectrum of nitrogenated ribbons quenched at (a) $30 \mathrm{~m} / \mathrm{s}$ and (b) $44 \mathrm{~m} / \mathrm{s}$.

results. We also observe an increase in the hyperfine field after nitrogenation of $20 \%$ in $8 \mathrm{i}$ sites (from $23.7 \mathrm{~T}$ to $28.5 \mathrm{~T}$ ) and $30 \%$ in $8 \mathrm{j}$ (from $17.3 \mathrm{~T}$ to $22.6 \mathrm{~T}$ ) and $8 \mathrm{f}$ (from $15.4 \mathrm{~T}$ to $19.8 \mathrm{~T}$ ) sites. This increase can be associated to the enhancement of the Curie temperature, which results in an increase of the ratio at room temperature to the saturation moment $\mathrm{M}(300 \mathrm{~K}) / \mathrm{M}(0 \mathrm{~K})$ by a similar amount. Regarding the $44 \mathrm{~m} / \mathrm{s}$ spectrum, the fitting was performed again by exactly replicating and later re-scaling the fitting spectrum obtained for the pure 1:12 nitrogenated sample $(30 \mathrm{~m} / \mathrm{s})$ and adding two paramagnetic contributions. The values of the hyperfine parameters of the paramagnetic phases are consistent to those obtained for the non-nitrogenated $44 \mathrm{~m} / \mathrm{s}$ sample. An additional $33 \mathrm{~T}$ spectrum was included for an optimum fitting, reflecting the presence of a bcc-(Fe,Mo) phase in the sample. However, there is a similar relative quantity of $\mathrm{Fe}$ in the $\mathrm{ThMn}_{12}$ phase for both the as-spun and nitrided samples, which evidences that the nitrogenation process has not induced any degradation in the 1:12 structure.

\subsubsection{Phase stability at high temperature under air}

There is high interest in permanent magnets working at moderately elevated temperature $\left(\geq 100{ }^{\circ} \mathrm{C}\right)$, particularly for the electrical motors applications, where the magnet is heated when spinning [2]. Hence, we decided to characterize the structural stability of our best sample above $100{ }^{\circ} \mathrm{C}$. When heating the nitrides, there is a possibility of loosing the nitrogen, which will be detrimental for the hard magnetic properties. A thermogravimetry measurement was then performed in air on the $30 \mathrm{~m} / \mathrm{s}$ nitride to determine at which temperature the nitrogen is leaving the structure. In Figure 10, we see that the mass is maintained constant below $400{ }^{\circ} \mathrm{C}$ (i.e. approx. below Curie temperature), which means that there is no loss of nitrogen in this range of temperature. Above $400{ }^{\circ} \mathrm{C}$, a large increase of mass is observed. This behavior should be due to the oxidation of the $\mathrm{Nd}$ and/or Fe, as the measurement was performed in air. Hence, the hard magnetic properties could deteriorate 


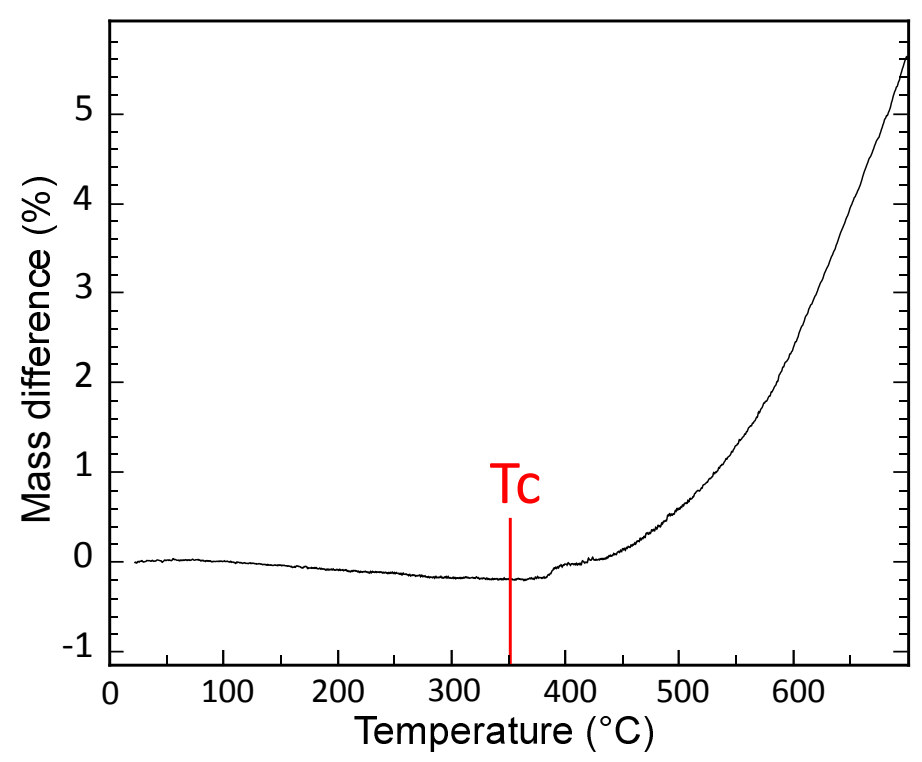

Figure 10: Thermogravimetry analysis under air of the $\mathrm{Nd}_{1.2} \mathrm{Fe}_{10.6} \mathrm{Mo}_{1.4} \mathrm{~N}$ quenched at $30 \mathrm{~m} / \mathrm{s}$.

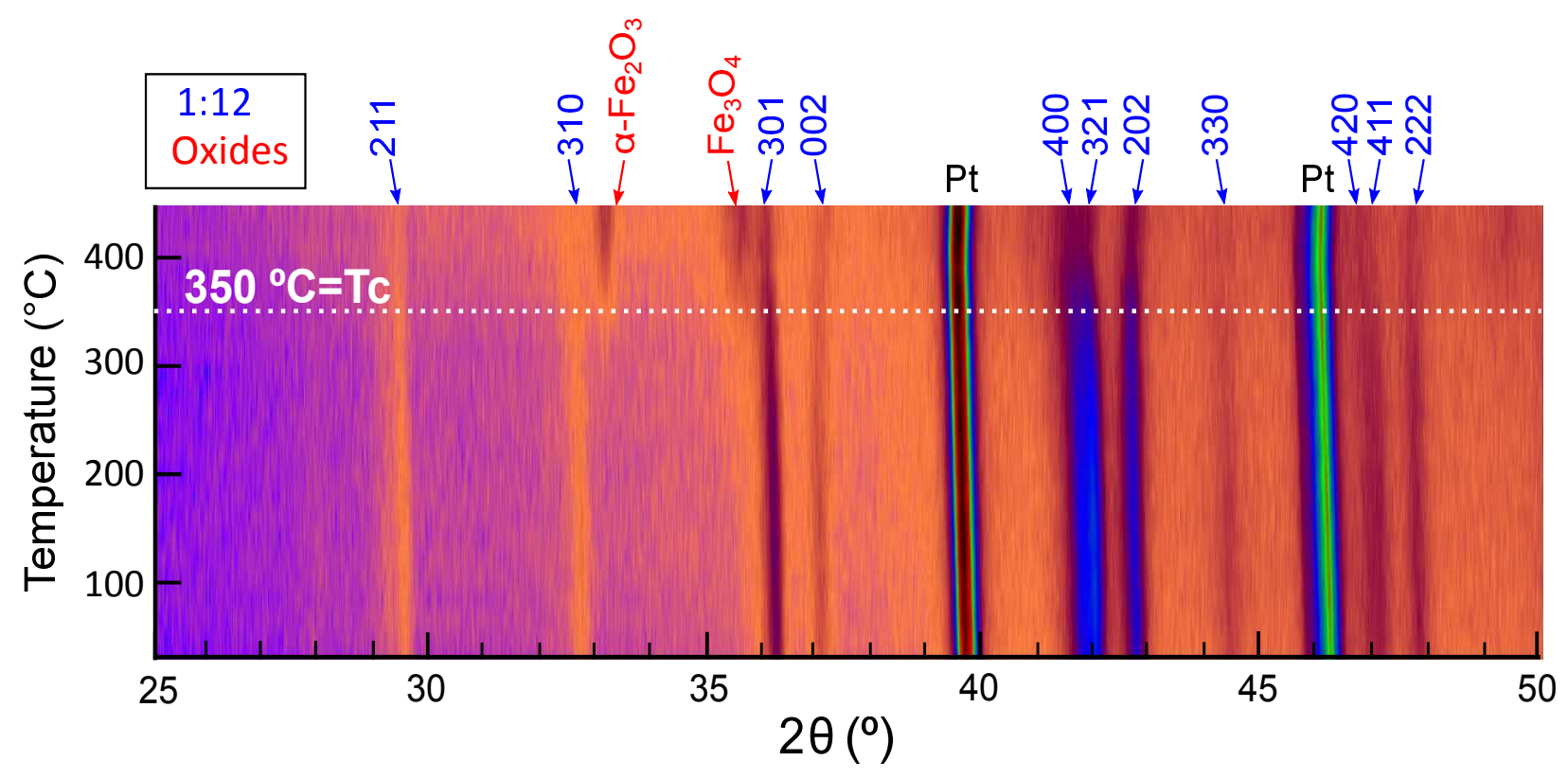

Figure 11: X-ray pattern obtained from $30{ }^{\circ} \mathrm{C}$ to $450{ }^{\circ} \mathrm{C}$ under air for the $\mathrm{Nd}_{1.2} \mathrm{Fe}_{10.6} \mathrm{Mo}_{1.4} \mathrm{~N}$ quenched at $30 \mathrm{~m} / \mathrm{s}$.

because of oxidation above $\mathrm{T}_{C}$, but not because of the loss of nitrogen.

$\mathrm{X}$-ray diffraction analysis as function of the temperature (in the range $25-400{ }^{\circ} \mathrm{C}$ ) under air has also been performed and is presented in Figure 11. No change in phase has been denoted below the Curie temperature, confirming the good stability of the $\mathrm{Nd}_{1.2} \mathrm{Fe}_{10.6} \mathrm{Mo}_{1.4} \mathrm{~N}_{x}$ structure. This measurement also confirms that above $400{ }^{\circ} \mathrm{C}$, there is formation of Fe-based oxides, mostly hematite $\left(\alpha-\mathrm{Fe}_{2} \mathrm{O}_{3}\right)$ and magnetite $\left(\mathrm{Fe}_{3} \mathrm{O}_{4}\right)$, which explains the increase in 
mass observed in TGA.

\section{Conclusion}

In summary, we investigated the structural and magnetic properties of rapidly quenched $\mathrm{Nd}_{1.2} \mathrm{Fe}_{10.6} \mathrm{Mo}_{1.4}\left(\mathrm{~N}_{x}\right)$ alloy. The increase of the quenching rate leads to a decrease of the grain size but can also induce a structural change. Moreover, Mossbauer spectroscopy revealed the presence of extra paramagnetic phases for samples quenched at elevated rates. These parameters (grain size, structure and magnetic ordering) have a direct influence on the hard magnetic properties of the compounds after nitrogenation. Indeed, for pure 1:12 nitride samples, the grain size is the main parameter influencing the coercivity. Hence, increasing the quenching rate is beneficial to optimize the nanostructure and consequently the coercivity. On the other hand, once a critical quenching rate is reached $(\geq 35 \mathrm{~m} / \mathrm{s})$, the nitrides obtained from non-pure 1:12 samples exhibit a decrease of the coercivity, mostly attributed to the impurities (amorphisation, paramagnetic ordering, etc). Hence, the best magnetic properties are achieved for a pure 1:12 sample with a coercivity of $0.6 \mathrm{~T}$, a saturation magnetization of $1.15 \mathrm{~T}$ and a Curie temperature of $350{ }^{\circ} \mathrm{C}$. The average grain size for this sample is approximately $250 \mathrm{~nm}$. The structural stability at elevated temperature for pure 1:12 nitride has also been investigated, demonstrating that we have a stable phase up to the Curie temperature. The study shows the large potential of the NdFeMo-based nitrides with $\mathrm{ThMn}_{12}$ structure for permanent magnet application.

\section{Aknowledgments}

The authors thank for technical and human support provided by SGIker (UPV/EHU) and particularly the services of: X-Ray Molecules and Materials (Dr. Aitor Larrañaga Varga), Magnetic Measurements (Dr. Iñaki Orue) and Electronic Microscope of Biomedicine (Dr. Alejandro Diez). We also thanks Dr. José Manuel Laza for his assistance in TGA measurements. This work has received funding from the European Union's Horizon 2020 research and innovation program under grant agreement No 686056 (NOVAMAG). 


\section{References}

[1] J. Cui, M. Kramer, L. Zhou, F. Liu, A. Gabay, G. Hadjipanayis, B. Balasubramanian, D. Sellmyer, Current progress and future challenges in rare-earth-free permanent magnets, Acta Mater. 158 (2018) 118. doi:10.1016/j.actamat.2018.07.049.

[2] K.P. Skokov and O. Gutfleisch, Heavy rare earth free, free rare earth and rare earth free magnets Vision and reality, Scr. Mater. 154 (2018) 289 - 294. doi:10.1016/j.scriptamat.2018.01.032.

[3] K. Ohashi, T. Yokoyama, R. Osugi, Y. Tawara, The magnetic and structural properties of R-Ti-Fe ternary compounds, IEEE Trans. Magn. 23 (5) (1987) 3101-3103. doi:10.1109/TMAG.1987.1065256.

[4] F. D. Boer, Y.-K. Huang, D. D. Mooij, K. Buschow, Magnetic properties of a series of novel ternary intermetallics $\left(\mathrm{RFe}_{10} \mathrm{~V}_{2}\right)$, J. Less Common Metals 135 (2) (1987) 199 - 204. doi:10.1016/00225088(87)90481-4.

[5] A. Gabay, G. Hadjipanayis, Recent developments in $\mathrm{RFe}_{12}$-type compounds for permanent magnets, Scr. Mater. 154 (2018) 284 - 288. doi:10.1016/j.scriptamat.2017.10.033.

[6] P. Tozman, H. Sepehri-Amin, Y. Takahashi, S. Hirosawa, K. Hono, Intrinsic magnetic properties of $\mathrm{Sm}\left(\mathrm{Fe}_{1-x} \mathrm{Co}_{x}\right)_{11} \mathrm{Ti}$ and $\mathrm{Zr}$-substituted $\mathrm{Sm}_{1-y} \mathrm{Zr}_{y}\left(\mathrm{Fe}_{0.8} \mathrm{Co}_{0.2}\right)_{11.5} \mathrm{Ti}_{0.5}$ compounds with $\mathrm{ThMn}_{12}$ structure toward the development of permanent magnets, Acta Mater. 153 (2018) $354-363$. doi:10.1016/j.actamat.2018.05.008.

[7] D. Simon, H. Wuest, T. Koehler, A. Senyshyn, H. Ehrenberg, O. Gutfleisch, The quaternary system $\mathrm{Sm}-\mathrm{Fe}-\mathrm{Mo}-\mathrm{Al}$ and the effect of Al substitution on magnetic and structural properties of its $\mathrm{ThMn}_{12}$ phase, J. Alloys Compd. 770 (2019) 301 - 307. doi:10.1016/j.jallcom.2018.08.030.

[8] A.-M. Schönhöbel, R. Madugundo, A. Gabay, J. Barandiaran, G. Hadjipanayis, The Sm-Fe-V based 1:12 bulk magnets, J. Alloys Compd. 791 (2019) 1122 - 1127. doi:10.1016/j.jallcom.2019.03.249.

[9] J.-M. Barandiaran, A. Martin-Cid, A.-M. Schönhöbel, J.-S. Garitaonandia, M. Gjoka, D. Niarchos, S. Makridis, A. Pasko, A. Aubert, F. Mazaleyrat, G. Hadjipanayis, Nitrogenation and sintering of (Nd$\mathrm{Zr}) \mathrm{Fe}_{10} \mathrm{Si}_{2}$ tetragonal compounds for permanent magnets applications, J. Alloys Compd. 784 (2019) 996 - 1002. doi:10.1016/j.jallcom.2019.01.044.

[10] C. Christides, A. Kostikas, A. Simopoulos, D. Niarchos, G. Zouganelis, A study of spin reorientation in $\mathrm{NdFe}_{12-x} \mathrm{~V}_{x}$ by Mossbauer and magnetization measurements, J. Magn. Magn. Mater. 86 (2) (1990) 367 - 376. doi:10.1016/0304-8853(90)90145-G.

[11] Q. Qi, B. Hu, J. M. D. Coey, 57Fe Mossbauer studies of $\mathrm{Nd}\left(\mathrm{Fe}_{12 x} \mathrm{Mo}_{x}\right)$ and $\mathrm{Nd}\left(\mathrm{Fe}_{12 x} \mathrm{Mo}_{x}\right) \mathrm{N}_{0.9}(\mathrm{x}=1.25$ and 1.50), J. Appl. Phys. 75 (10) (1994) 6235-6237. doi:10.1063/1.355409.

[12] E. H. C. P. Sinnecker, X. C. Kou, R. Grossinger, Magnetocrystalline anisotropy and spin reorientation in $\mathrm{NdFe}_{12-x} \mathrm{Mo}_{x}$ and $\mathrm{NdFe}_{12-x} \mathrm{Mo}_{x} \mathrm{~N}_{y}$ compounds ( $\mathrm{x}=0.5,1.0,2.0,3.0,4,0$ and $\mathrm{y}=1.0$ ), IEEE Trans. Magn. 31 (6) (1995) 3707-3709. doi:10.1109/20.489702.

[13] M. Anagnostou, C. Christides, M. Pissas, D. Niarchos, Preparation and characterization of the $\mathrm{NdFe}_{10} \mathrm{~T}_{2} \mathrm{~N}_{x}(\mathrm{~T}=\mathrm{Mo}, \mathrm{V})$ compounds with the $\mathrm{ThMn}_{12}$ tetragonaltype structure, J. Appl. Phys. 70 (10) (1991) 6012-6014. doi:10.1063/1.350077.

[14] Y.-C. Yang, X.-D. Zhang, L.-S. Kong, Q. Pan, S.-L. Ge, New potential hard magnetic material $\mathrm{NdTiFe}_{11} \mathrm{~N}_{x}$, Sol. Stat. Comm. 78 (4) (1991) 317 - 320. doi:10.1016/0038-1098(91)90205-A.

[15] H.-S. Li, J. Cadogan, Determination of the leading crystal-field parameter $\mathrm{A}_{20}$ in $\mathrm{NdFe}_{11} \mathrm{Ti}_{1} \mathrm{~N}$ compounds, J. Magn. Magn. Mater. 109 (2) (1992) L153 - L158. doi:10.1016/0304-8853(92)91742-C.

[16] M. Endoh, K. Nakamura, H. Mikami, $\mathrm{Nd}(\mathrm{Fe}, \mathrm{Mo})_{12} \mathrm{~N}_{x}$ compounds and magnets, IEEE Trans. Magn. 28 (5) (1992) 2560-2562. doi:10.1109/20.179556.

[17] B. Hu, H. Li, J. M. D. Coey, Relationship between $\mathrm{ThMn}_{12}$ and $\mathrm{Th}_{2} \mathrm{Ni}_{17}$ structure types in the $\mathrm{YFe}_{11-x} \mathrm{Ti}_{x}$ alloy series, J. Appl. Phys. 67 (9) (1990) 4838-4840. doi:10.1063/1.344753.

[18] A. Margarian, J. B. Dunlop, R. K. Day, W. Kalceff, Phase equilibria in the Ferich corner of the NdFeTi ternary alloy system at 1100 C, J. Appl. Phys. 76 (10) (1994) 6153-6155. doi:10.1063/1.358338.

[19] F. Maccari, L. Schfer, I. Radulov, L. Diop, S. Ener, E. Bruder, K. Skokov, O. Gutfleisch, Rapid solidification of $\mathrm{Nd}_{1+x} \mathrm{Fe}_{11} \mathrm{Ti}$ compounds: Phase formation and magnetic properties, Acta Mater. 180 (2019) 15 - 23. doi:10.1016/j.actamat.2019.08.057. 
[20] J. Yang, P. Oleinek, K.-H. Mller, Hard magnetic properties of melt-spun $\mathrm{R}(\mathrm{Fe}, \mathrm{M})_{12}$ nitrides $(\mathrm{R}=\mathrm{Nd}$ or Pr; M=Mo or V), J. Appl. Phys. 88 (2) (2000) 988-992. doi:10.1063/1.373766.

[21] Z. Lin, J. Han, S. Liu, M. Xing, Y. Yang, J. Yang, C. Wang, H. Du, Y. Yang, Phase composition, microstructures and magnetic properties of melt-spun $\mathrm{Nd}_{1.2} \mathrm{Fe}_{10.5} \mathrm{Mo}_{1.5}$ ribbons and their nitrides, $\mathrm{J}$. Magn. Magn. Mater. 324 (2) (2012) 196 - 199. doi:10.1016/j.jmmm.2011.08.009.

[22] X. Kong, J. Han, S. Liu, Z. Lin, C. Wang, J. Yang, H. Du, Y. Yang, Nitrogenation effect of $\mathrm{Nd}(\mathrm{Fe}, \mathrm{Mo})_{12}$ alloys prepared by strip casting technique, J. Alloys Compd. 506 (2) (2010) $858-861$. doi:10.1016/j.jallcom.2010.07.095.

[23] J. B. Fu, X. Yu, Z. Q. Qi, W. Y. Yang, S. Q. Liu, C. S. Wang, H. L. Du, J. Z. Han, Y. C. Yang, J. B. Yang, Magnetic properties of $\mathrm{Nd}\left(\mathrm{Fe}_{1-x} \mathrm{Co}_{x}\right)_{10.5} \mathrm{M}_{1.5}(\mathrm{M}=\mathrm{Mo}$ and $\mathrm{V})$ and their nitrides, AIP Adv. 7 (5) (2017) 056202. doi:10.1063/1.4973207.

[24] F. E. Pinkerton, C. D. Fuerst, J. F. Herbst, Nitriding of meltspun Nd-FeMo alloys, J. Appl. Phys. 75 (10) (1994) 6015-6017. doi:10.1063/1.355493.

[25] Z. Tang, G. Hadjipanayis, V. Papaefthymiou, Intrinsic and hard magnetic properties of rapidly quenched $\mathrm{NdFe}_{10} \mathrm{Mo}_{2} \mathrm{~N}_{x}$ ribbons, J. Alloys Compd. 194 (1) (1993) 87 - 91. doi:10.1016/0925-8388(93)90650C.

[26] I. Popa, P. de Rango, D. Fruchart, S. Rivoirard, High-speed forged $\mathrm{NdFe}_{12-X} \mathrm{~V}_{X}$ compounds for bonded magnets, J. Magn. Magn. Mater. 242-245 (2002) 1388 - 1390. doi:10.1016/S0304-8853(01)01241-0.

[27] H. Fiedler, H. Mühlbach, G. Stephani, The effect of the main processing parameters on the geometry of amorphous metal ribbons during planar flow casting (PFC), J. Mater. Sci. 19 (10) (1984) 3229-3235. doi:10.1007/BF00549809.

[28] Q. F. Xiao, Z. D. Zhang, T. Zhao, W. Liu, Y. C. Sui, X. G. Zhao, D. Y. Geng, Crystallographic transformations of rapidly quenched sm10fe90-xtix and magnetic properties of their nitrides, Journal of Applied Physics 82 (12) (1997) 6170-6176. doi:10.1063/1.366501.

[29] W. Liu, Z. Zhang, J. Liu, X. Sun, D. Sellmyer, X. Zhao, Phase constitution and magnetic properties of $\mathrm{Nd}_{10} \mathrm{Fe}_{76} \mathrm{~B}_{4} \mathrm{M}_{10}$ and $\mathrm{Nd}_{10} \mathrm{Fe}_{76} \mathrm{~B}_{2} \mathrm{M}_{12}(\mathrm{M}=\mathrm{Fe}, \mathrm{Ti}, \mathrm{V}, \mathrm{Cr}, \mathrm{Mn}, \mathrm{Co}$ and $\mathrm{Al})$ alloys prepared by mechanical alloying, J. Magn. Magn. Mater. 221 (3) (2000) 278 - 284. doi:10.1016/S0304-8853(00)00511-4.

[30] T. Sinnemann, K. Erdmann, M. Rosenberg, K. H. J. Buschow, A Mossbauer and NMR spectroscopy study of $\mathrm{RFe}_{12-x} \mathrm{M}_{x}$ intermetallics, Hyperfine Interact. 50 (1) (1989) 675-683. doi:10.1007/BF02407707.

[31] C. Denissen, R. Coehoorn, K. Buschow, 57Fe Mossbauer study of $\mathrm{RFe}_{12-x} \mathrm{~T}_{x}$ compounds $(\mathrm{T}=\mathrm{V}, \mathrm{Cr}$, Mo), J. Magn. Magn. Mater. 87 (1) (1990) 51 - 56. doi:10.1016/0304-8853(90)90193-T.

[32] B. Cui, X. Sun, L. Xiong, S. Cao, X. Zhang, W. Liu, D. Geng, Z. Zhang, Relation between structure and magnetic properties of $\mathrm{Nd}_{2}(\mathrm{Fe}, \mathrm{Co}, \mathrm{Mo})_{14} \mathrm{~B} / \mathrm{a}-\mathrm{Fe}$ nanocomposite magnets, J. Alloys Compd. 340 (1) (2002) 242 - 251. doi:10.1016/S0925-8388(02)00014-2.

[33] K. Fukamichi, R. Gambino, The curie temperature and magnetization of fe-base amorphous binary alloys containing transition metal, IEEE Transactions on Magnetics 17 (6) (1981) 3059-3061. doi:10.1109/TMAG.1981.1061592.

[34] M. Akayama, H. Fujii, K. Yamamoto, K. Tatami, Physical properties of nitrogenated $\mathrm{RFe}_{11} \mathrm{Ti}$ intermetallic compounds $(\mathrm{R}=\mathrm{Ce}, \mathrm{Pr}$ and $\mathrm{Nd})$ with $\mathrm{ThMn}_{12}$-type structure, J. Magn. Magn. Mater. 130 (1) (1994) 99 - 107. doi:10.1016/0304-8853(94)90662-9. 